\title{
DO SONHO DOS INVIDENTES ÀS MIRAGENS DA MEMÓRIA
}

\author{
FROM THE SIGHTLESSES'S DREAMS TO THE MEMORY'S MIRAGES
}

\begin{abstract}
André Winter Noble ${ }^{1}$
RESUMO: Este ensaio parte do livro "O Que os Cegos Estão Sonhando?" da escritora e crítica literária brasileira Noemi Jaffe, obra que divulga a relação de três mulheres (avó, mãe e filha) com a Shoah, narrativa que tem como cenário, a vivência e a sobrevivência a um dos campos de concentração e extermínio nazista. O livro expõe o distanciamento do acontecimento, do campo, mas igualmente nos permite dizer que quanto mais as gerações vão se afastando do fato, mais rente a ele estão. Para dizer dessas relações, investimos em um discurso que percorre por entre as questões da memória, do esquecimento e da ficcionalização mnemônica, afora a própria construção discursiva e monumental.

Palavras-chave: "O que os cegos estão sonhando?"; memória e esquecimento; linguagem da/na guerra.
\end{abstract}

ABSTRACT: This essay is from the book "What Are the Blind Dreaming?" by the brazilian writer and literary critic Noemi Jaffe, a work that discloses the relationship of three women (grandmother, mother and daughter) with Shoah, narrative that takes as its setting, the experience and survival of one of the Nazi concentration and extermination camps. The book exposes the distance from the event, from the field, but it also allows us to say that the further generations go away from the fact, the closer they are to it. To speak of these relationships, we invest in a discourse that runs through the issues of memory, forgetting and the mnemonic fictionalization, beyond the monumental and discursive construction itself.

Keywords: "What the blind are dreaming?"; memory and forgetfulness, language of/in war.

Lembrar, cada vez mais, não é recordar uma história, e sim ser capaz de evocar uma imagem.

(Susan Sontag, 2003, p. 21)

É o poeta João Cabral de Melo Neto quem, em seu poema Catar Feijão, A Alexander O’Neill, nos diz:

Catar feijão se limita com escrever: jogam-se os grãos na água do alguidar e as palavras na da folha de papel; e depois joga-se fora o que boiar. Certo, toda palavra boiará no papel,

\footnotetext{
${ }^{1}$ Doutor em Letras - Estudos de Literatura/Teoria, Crítica e Comparatismo pela Universidade Federal do Rio Grande do Sul - UFRGS.
} 
água congelada, por chumbo seu verbo: pois, para catar esse feijão, soprar nele, e jogar fora o leve e oco, palha e eco.

2

Ora, nesse catar feijão entra um risco: o de que entre os grãos pesados entre um grão qualquer, pedra ou indigesto, um grão imastigável, de quebrar dente. Certo, não, quando ao catar palavras: a pedra dá à frase seu grão mais vivo: obstrui a leitura fluviante, flutual, açula a atenção, isca-a com o risco. ${ }^{2}$

Neste caso, neste causo quase, João Cabral nos dá a ler e a ver, talvez, seu movimento de escrita, sua vontade verbal, seu modo de lapidação da língua, sua maneira de lidar com a linguagem. Mas poderíamos igualmente nos apropriar desse gesto seletivo, fundamental para qualquer construção discursiva para pensar, mais uma vez, a escrita não apenas da poesia, mas da prosa, do relato, da memória. O ato de selecionar (no caso, "a pedra", aquilo que atrapalha e faz trepidar, de Sísifo a Drummond) é gesto basilar nesse fragmento poético, cabralino; o movimento seletivo é fundamental na construção ficcional, é inquebrantável na transformação discursiva do ato de lembrar. Rememorar é selecionar aquilo que boia ou que afunda na memória, no alguidar craniano ou aquilo que fica ou passa pela trama das artérias e veias ao retornar ao coração (do latim, recordis, voltar ao coração).

Falamos em transformações discursivas, levando em consideração o caráter ficcional da memória; dela, não como uma inverdade ou invenção, mas como um mosaico, edificado, ora por fragmentos lapidados, ora por restos, estilhaços justapostos e unidos por uma massa sempre úmida, sempre passível de esfacelamento, um chumbo que nunca enrijece, nunca obtura. E pensar o gesto de selecionar como uma chave-de-leitura ou olho-mágico para acessar um texto parece uma proposta bastante rendosa: a seleção da memória, do editor, o ato de escolher entre o que boia e o que afunda.

Lembrar e esquecer são coisas muito parecidas. São processos mnemônicos seletivos, relacionados ao passado - imediato ou distante - carregados de invenção e realidade. Se nós lembramos não somente o que aconteceu, mas também o que gostaríamos que tivesse acontecido, por que também não se pode dizer que esquecemos coisas que não aconteceram, ou que não gostaríamos que tivesse acontecido? (JAFFE, p. 165).

Para tratar desse gesto, desse movimento seletivo, podemos recorrer a muitos textos, mas certamente encontraremos exemplos marcantes entre os da chamada Literatura de Testemunha, campo marcado, maiormente pela exposição das cicatrizes intradermes. Estigmas e gilvazes os quais só podemos ter uma vaga ideia através do relato daqueles que as trazem inscritas na pele. A semântica das cicatrizes: através dela, lemos a profundidade de cada marca, o instrumento cortante, o comprimento do sinal, a fundura da dor. Tudo isso alguns indivíduos tentam contar, tentam narrar mesmo sabendo da sua impossibilidade. A memória é uma espécie de

\footnotetext{
${ }^{2}$ (MELO NETO, 2003, pp. 320 - 321).
} 
cicatriz, seja ela orgânica ou geométrica, uma cicatriz que ora se esconde, ora se mostra. Podemos relacionar a memória à cicatriz, porque esta, tal como aquela, pode ser interpretada como resto de um sacrifício, a escritura da dor que perdeu sua intensidade, aquilo que fica de um momento de agonia, a caligrafia da chibata. A palavra cicatriz provém do vocábulo latino č̆cātricīcem, que pode estar relacionado tanto à marca de uma árvore quanto a de uma ferida. A cicatriz é o atestado de proficiência do sobrevivente.

Fotos do sofrimento e do martírio de um povo são mais do que lembranças de morte, de derrota, de vitimização. Elas evocam o milagre da sobrevivência. Ter por objetivo a perpetuação das memórias significa, de forma inevitável, que se assumiu a tarefa de continuamente renovar e criar memórias - com a ajuda, sobretudo, da marca deixada por fotos exemplares. As pessoas querem ser capazes de visitar - e revigorar - suas memórias. Agora, muitos povos vitimados desejam um museu da memória, um templo para abrigar uma narrativa de seus sofrimentos que seja abrangente, organizada de forma cronológica e ilustrada. (SONTAG, p. 21).

Já que relacionamos a figura da cicatriz à memória, podemos complementar observando que a memória é a chama que precisa de constante abano, ou ainda, a ferida do menino que nunca cicatriza e, nesse sentido, as narrativas, os relatos, as imagens dos fatos são o machucado que precisa ser mostrado, desvelado pelo dedo do menino, aquele que sempre volta à ferida, evitando que ela cicatrize, impedindo que os acontecimentos históricos, que o passar dos dias, não envolvam em derme esse pedaço de carne e dor. A memória, para a história, é como a ferida para o hemofílico.

Sobre uma dessas feridas, tomemos com o livro da paulista Noemi Jaffe, intitulado O Que os Cegos Estão Sonhando?. Este livro, publicado em 2012 pela Editora 34, traz o relato de três mulheres atingidas direta ou indiretamente pela guerra: a neta (Leda Cartum), a filha (Noemi Jaffe) e a mãe (Lili Jaffe), sobrevivente de um dos campos de tortura do exército nazista. Quem seleciona os fragmentos a serem mostrados (inclusive do diário) e assina o livro é a escritora, mãe, filha e crítica literária Noemi Jaffe, que decide abrir o seu livro com o diário de sua mãe, Lili Jaffe: diário que revela alguns dos dias (sobre e sub) vividos entre 1944 - 45 e documentados em 1945, após o final da Segunda Grande Guerra, depois da libertação dos campos de concentração, trabalho e extermínio, quando o "Macht Frei" foi, finalmente, cumprido. Pois, para a confecção desse diário (escrito a posteriori), Lili joga no alguidar da página, mancheias de letras carregadas de inocência e consternação, fragmentos discursivos que se reúnem em montes, excertos correspondentes às jornadas suportadas, aos dias existidos entre 1944 e 1945. Seus olhos veem e suas mãos relatam o que pode a maldade humana:

Todos os anos, em setembro fazem uma seleção nos campos em que ficam aqueles que não trabalham. Assim, levavam mulheres vivas, em carroças e caminhões, para o crematório. Podíamos ver isso. Chovia. As mulheres estavam sentadas nas carroças e os homens as puxavam até o crematório. Aquelas que eram um pouco mais fortes tentavam escapar, mas os alemães sempre as fuzilavam. Eram gritos de lamentação desde a manhã até a noite. Ouvíamos os tiros. Não quis sair da cozinha. Chorávamos. Quando saí (porque precisava sair), via somente chamas ao redor. Ficaram acesas durante três dias inteiros. (JAFFE, p. 27). 
Tal como os relatos de Primo Levi, Elie Wiesel, e tão poucos outros, os de Lili Jaffe sequer podem ser discutidos, não há palavras para dizer a partir das suas. Por mais que se tente expressar em palavras, em imagens, em linguagem todo o horror suportado nos campos de tortura e extermínio nazista (e ainda hoje em diversas partes do mundo), não há possibilidade de dar conta: a linguagem é tão fraca, nesse sentido, quanto o próprio e fracassado homem.

Enquanto que para a maldade não há limites, para a linguagem talvez haja e talvez os próprios gritos de ordem e dor, esses urros que quase escapam da língua, que quase criam outro idioma, seja a única expressão possível para, minimamente, nos aproximar do horror. No entanto, essa espécie de língua, característica do duplo demens será constituída por uma encenação, porque felizmente elas são apartadas do contexto que as gerou. Por mais que qualquer de nós grite o mais rispidamente possível uma palavra como, por exemplo, Schnell, ela será a ficcionalização, uma espécie de paródia, a performativização daquele Schnell que, na década de 30 e 40 do século XX, num determinado contexto, tinha outros significados atrelados. Afora o som cortante e monossílabo daquele Schnell emitido por algum verdugo nazista, deve-se levar em consideração o destinatário específico desse imperativo. Para melhor dizer dessa linguagem dos campos, podemos apenas espelhar trechos mencionados por Noemi Jaffe à página 119 , na segunda parte do livro.

Ao fazer menção às palavras alemãs Geld, Trinkt, Essen, Nicht, Ja, afora o próprio e sempre cortante Schnell, é como se ela nos alertasse para determinado caráter não apenas "monossilábico" dessas expressões, mas também intransigente daquela língua. E nos dirigimos àquela língua, tendo em vista a língua alemã de determinada época, em determinado contexto.

De volta à impossibilidade da língua/das linguagens em dar conta de determinadas situações-limite, lembremo-nos o que disse Henry James, a respeito da Primeira Grande Guerra, ao jornal The New York Times: Em meio a tudo isso, é tão difícil fazer uso das palavras como suportar os pensamentos. A guerra esgotou as palavras; elas se enfraqueceram, deterioraram-se [...] (JAMES Apud: SONTAG, p. 9).

A ordem, a burocracia, são meios que não levam a fins. Meios que servem a si próprios. Uma linguagem que gira eternamente em falso, em torno de si mesma, sugando os homens, as instituições, os valores, as possibilidades. É uma mediação infinita, que se autoalimenta e cria uma ilusão de conteúdo, quando, na verdade, não passa de exigência para um conteúdo eventual. Uma língua sem significado, só significante vazio. (JAFFE, p. 121).

Se examinarmos outros idiomas, talvez encontremos equivalentes para o Schnell mencionado por Noemi Jaffe. Schnell seria talvez traduzido por Subayaku nas filiais japonesas dos campos de tortura (lembremo-nos da Unidade 731 que, desde 1930, fez os mais cruéis experimentos com seus vizinhos chineses e coreanos) ou traduzido por Rapidment nas filiais francesas. Mas talvez nem Rapidment, nem mesmo Subayaku sejam capazes de atravessar a alma, fazer implodir o corpo tal como a sonoridade de um Schnell. Nesse sentido, poderíamos nos perguntar, seria a barbárie uma outra língua, uma outra linguagem ou seria ela (a barbárie) mais um anexo intrínseco a cada uma (língua/linguagem), assim como a maldade é o candeeiro sempre aceso nos espaços vazios do corpo humano? 
Depois de ter sustentado a pedra, fiquei com a pele do joelho toda rasgada. Os alemães chamaram para uma nova seleção e, dessa vez, era o Mengele que iria nos examinar. Fiquei com muito medo. Ele era muito detalhista. Eu estava nua, mas fiquei carregando minhas roupas sobre os joelhos, para que ele não visse. Eu tinha uma aparência boa e, por sorte, ele não viu meus joelhos e me deixou passar. (JAFFE, p. 116).

A pedra, a única certeza, um dos únicos acontecimentos "não-ficcionalizados", concisos, do início ao fim da narrativa, o único elemento que não pode ser escolhido no alguidar, mas que foi despejado sobre a cabeça, é uma das marcas desse texto, certamente uma espécie de monumento à barbárie, à desrazão, à irrazão, à gratuidade do mal. A pedra e ela, Lili Jaffe, naquele momento, desde aquele dia, são como um monumento, o avesso dele. Primeiro, porque torna o sujeito a própria base para erguer um fragmento banal do solo alemão e, segundo, porque objetifica, petrifica, abstrai a própria figura humana, faz dela uma nova Cariátide, um Atlante, uma Atlas, devolve a escultura à arquitetura que a "originou", devolve a escultura à monumentalidade que a "originou". Lili e a pedra, pedra escolhida pelo seu peso (por ser tão pesada quanto ela), inverte a lógica do monumento ainda que mantenha uma lógica de engenharia: a fundação deve ser tão forte quanto o restante da construção, no entanto, lidamos com uma base de carne e sensibilidade epidérmica que é obrigada a erguer qualquer coisa rígida e congelante. Um monumento do avesso, com aquilo que deveria ser a base, no topo.

Como pilares de uma grande muralha, os monumentos são em geral levantados em honra dos vencedores, "emparedando seus construtores". Trabalhadores que por fim, ao constituírem a ossatura de cada colosso, tornam-se invisíveis ou grifam tal invisibilidade já latente não apenas aos olhos dos passantes, mas sobretudo àquela figura que os encima e até então segue a lhes pesar os ombros. Figuras metálicas ou pétreas a coroarem qualquer base, a impossibilitarem o enrijecimento de qualquer espécie de massa construtiva. Há sempre algo imperativo e tirânico nos multiformes sopros que, empreendidos sobre os assujeitados, os congela de modo a mais do que arrebatarem, mas petrificarem e quase impossibilitarem qualquer gesto de recusa ou esquiva.

Uma vez encetada a discussão que nos leva à construção deste artigo e ainda a tentativa de dizer contra a imposição de um dizer, vale recorrermos a dois autores fundamentais para a incitação de qualquer apêndice significativo a respeito do termo "monumento". De acordo com escritos de intelectuais e historiadores como Alois Riegl e Jacques Le Goff, o conceito de monumento referencia um objeto inscrito por um gesto encarregado pela recuperação de certa narrativa ou sujeito, ancorando ou materializando tal discurso em uma alegoria ou elemento simbólico e de projeção marcadamente pública. Não é à toa que historicamente os tiranos e usurpadores que chegam ao poder cercam-se de grupos de artífices e midiáticos, cegados pelas ideologias estadeadas pelos seus patrões, que aceitam entregar sua força de trabalho para criar um aspecto lendário e quase divino na promoção da imagem desse sujeito mitificado. Que os iconoclastas se mantenham sempre alertas e atentos aos rastros deixados pelos discursos proferidos em hálito, pedra, metal ou tinta! Urge que seja pensado o contra-monumento, artefato responsável pela iluminação dos rodapés da história, considerando sobretudo os iletrados, mantidos assim para que justamente não a possam escrever.

Em seu Culto Moderno dos Monumentos, Alois Riegl se debruçará sobre questões como o valor de arte (Kunstwert) e a vontade de arte (Kunstwollen), no entanto interessa-nos recuperar para este texto a conceituação que o historiador austríaco faz de monumento para dizer das 
formas de culto. Assim sendo, o teórico propõe sua teoria a partir da subdivisão das obras em monumentos históricos voliveis e não voliveis, cujas maneiras de culto se dão de maneira diversa, da forma ancestral para o modo percebido em sua época. Lembremo-nos que, escrito em 1903, tal texto (Der Moderne Denkmalkultus) parte de um contexto que dará origem ao poema "A Perda da Auréola", de Charles Baudelaire, a Negerplastik, de Carl Einstein, e desembocará na "Perda da Aura”, que é concepção cara à averiguação de Walter Benjamin. Os pensadores mencionados, pertencem, portanto a um momento histórico em que o culto e toda a gestualidade pertencente a esse campo de doação e devoção estava sendo posta em xeque pelos pensadores da época. E ainda.

Tendo em vista tais particularidade do contexto de lançamento do livro, cabe salientar que a denominação de monumento, segundo a concepção de Alois Riegl, deve ser entendida não em sentido objetivo, mas em sentido subjetivo. Seu significado e importância não provêm da sua destinação original, mas daquilo que nós sujeitos modernos atribuimos a eles. Nos dois casos, de monumentos volíveis e não voliveis, trata-se de valores de memória e por isso falamos em "monumentos". Não obstante, faz-se mister aqui recuperarmos certo aspecto etimológico imediatamente explorado por Jacques Le Goff, tentando remontar um étimo da suposta origem do termo monumento, contíguo a uma espécie de "sopro recordatório" ou a "recuperação de uma virtualidade". Sem embargo, vale ressaltar que nos monumentos voliveis, definidos assim por Riegl, o valor de memória é atribuído pelo autor, particularidade contrária aos monumentos não voliveis, nos quais tal valoração é atribuída pelos seus espectadores. (RIEGL, 2004, p. 36).

Conforme recém-apregoado, a fim de complementar a leitura supracitada, cabe replicarmos as palavras de Jacques Le Goff, impressas no livro História e Memória, espaço no qual o autor relaciona o termo monumento à palavra latina monumentum, a qual remete para a raiz indo-européia men, que exprime uma das funções essenciais do espírito (mens), a memória (meminí). $\mathrm{O}$ verbo monere significa 'fazer recordar', de onde 'avisar', 'iluminar', 'instruir'. O monumentum é um sinal do passado. Atendendo às suas origens filológicas, o monumento é tudo aquilo que pode evocar o passado, perpetuar a recordação, por exemplo, os atos escritos. (LE GOFF, 1990, p. 535). Não obstante, tendo em vista que as palavras e imagens também evocam a situações outrora vivenciadas, poderíamos ainda considerar determinadas obras, construídas a partir do trabalho com a linguagem, também como monumentos. A literatura, por exemplo, pode ser percebida como um monumento, ou mesmo um contra-monumento.

Uma vez cabendo aos monumentos a incumbência de presentificar uma ausência, consequentemente, esses marcos simbólicos vêm a consistirem em um significante e ainda uma quase-alegoria. Assim sendo, vale pensarmos as Artes como o lugar de confluência de narrativas espaço-temporais; lugar onde se experiencia as multiformes tentativas de fixação do instante; lugar onde se ensaia o dizer valendo-se do máximo de artifícios miméticos, metafóricos ou metonímicos, ou ainda se busca dizer ou reivindicar um dizer justamente pelo mínimo-dizer ou ainda pelo não-dizer.

Para exemplificar tal assertiva, sem querer esgotar as leituras (já as depauperando), caberia relacionar certo artifício empregado durante as vanguardas artísticas, relacionado perfeitamente com o contexto de crise dos dizeres e, sobretudo de hecatombes. Momento que levaria intelectuais como o filósofo Theodor Adorno a, no final dos anos 1940, perguntar se haveria ainda possibilidade de fazer poesia após Auschwitz. Sem embargo, as Artes, ao insistirem na desconstrução da representação, no desprendimento com a figuração ou mesmo na sua total eliminação, estão igualmente dizendo da iminência de uma nova relação com o que está-aí e ao mesmo tempo nos alertando para esse mal-estar na cultura, indisposição criada 
junto com a própria ideia de cultura. Não havia mais o que dizer, porque nada poderia ser dito frente aquela realidade.

Ainda assim, por mais que os relatos de Lili Jaffe e os comentários da filha e da neta exprimam o horror, tal como os de todos aqueles que sobreviveram ou subviveram a/em uma das filiais do inferno terrestre; por mais que seus relatos se aproximem dos círculos mais profundos alcançados por Dante e Virgílio, os olhos de Lili Jaffe, nalgumas ocasiões, parecem até buscar algum resquício ou fagulha de humanidade, alguma centelha de luz no olhar dos carrascos, como no momento da seleção das 25 mulheres para trabalhar na cozinha: Estava furiosa. Mas brincou comigo. Chegou a gostar de mim. Deixou-me ficar e dispensou outras cinco. (JAFFE, p. 21)

Teria Lili realmente enxergado alguma bondade no olhar da kapo ou mirageado um sorriso estampado entre os lábios de quem rangia os dentes de raiva? Nesse sentido, quanto à questão da raiva, não apenas da kapo e dos alemães em relação às prisioneiras mas, sobretudo, da raiva sentida pelos sobreviventes, e verdadeiros vitoriosos em relação aos seus algozes, sobretudo alemães, nazistas. Cabem novamente as palavras de Noemi Jaffe, tendo as de Lili Jaffe como matriz de um aprendizado:

A supressão da raiva deve fazer parte do processo cirúrgico do esquecimento; sentir raiva significa alimentar a memória de fatos e histórias para que elas (a memória e a raiva) possam manter-se continuamente; para que elas sejam repassadas, para que se tornem um legado de muitas gerações. (JAFFE, 116).

E, ressalta, na página seguinte:

Como é difícil simplesmente odiar! Dizer o que se pensa, cuspir a raiva e dizer não quero, não gosto, não vou. A supressão da raiva cria uma personalidade concessiva e contemporizadora, que pode facilmente se confundir com generosidade integral. Possivelmente, toda grande generosidade esconde alguma grande raiva. As filhas sentem raiva por ela não sentir raiva? Primo Levi tem raiva, Elie Wiesel tem raiva, Ruth Klüger tem raiva, Jorge Semprún tem raiva. Para lembrar é preciso ter raiva; para ter paz é preciso esquecer. (JAFFE, 117).

Partindo desses apontamentos, poderíamos nos perguntar a quem deveríamos lançar, de fato, a nossa raiva. Aos alemães, que não se importaram com as nuvens que exalavam o cheiro de carne humana queimada e que tornaram o céu alemão menos azul? Aos judeus, que se deixaram dominar? Ao Sonderkommando e aos Kapos que se voltaram contra o próprio povo, seja fiscalizando, seja punindo, seja delatando, seja levando-o para o banho, seja retirando-o das câmaras de gás, seja levando-o ainda vivo para o crematório? Aos nazistas, por tudo? A Mengele, por tudo? A Hitler, por tudo? A Deus, por permitir tudo isso? Levando em consideração principalmente essas últimas indagações, cabe lembrar uma certeza sugerida por Noemi Jaffe à página 118. Ela remete para o fato que Mengele também acreditasse em alguma coisa, rezava para algum deus. Mas como não se perguntar que deus é esse que divide sua atenção entre Mengele e a mãe de Noemi e tantas outras, e tantos outros? Como não se indagar que deus é esse que divide sua atenção entre Hitler e aqueles por quem alimenta seu ódio, sua demência?

Esses apontamentos talvez nos permitam dizer que Deus seja não uma criação específica, 
um significado variável atribuído a um significante que está aí. Digamos de outra maneira: se Deus enquanto significado e enquanto presente-ausente, é considerado como criação humana, poderia ser considerado que cada sujeito, enquanto unidade ou coletivo, atribui a essa determinada presença-ausente (o Grande Significante, que precisou ser inventado para constituir o tempo e o humano, a culpa e o temor), o significado que melhor se adapte a determinados ideais, especificidades linguísticas e conjunto de verdades concebidos por cada povo. Como tratamos de significados, temos que levar em consideração a maleabilidade e a adaptabilidade deste significado.

Recuperando a questão anterior, tendo em vista que grande parte dos monumentos hoje conhecidos faz alusão a grandes batalhas e conquistas territoriais ou reverenciam tiranos e mártires, valeria recuperarmos a hipótese freudiana a respeito da primeira interdição e, de alguma forma, de um suposto nascimento da cultura. Assim sendo, é em Totem und Tabu (1913), que Sigmund Freud fabula uma suposta cena instauradora da cultura, valendo-se de uma apresentação do incesto originário, o qual é replicado de formas distintas na maior parte das culturas, ditas primitivas ou não; hipótese influenciada pelas ideias do antropólogo escocês Sir James G. Frazer, cujas descobertas e cotejos interculturais eram divulgados em livros como Totemism (1887) e Totemism and Exogamy (1910).

Portanto, o livro Totem e Tabu trabalhará em cima da hipótese do parricídio, ocasionado pela investida vingativa deflagrada pelos herdeiros daquele que monopolizava as mulheres do bando, organização supostamente anterior ao sistema de clãs. Assim sendo, o retorno dos filhos expulsos do bando criara um ritual de assassínio e imediata antropofagia do pai morto, impondo ao grupo um novo sistema de regras e divisões em clãs. Não obstante, uma vez sacrificado o pai, a sua falta retornaria ao grupo em forma de angustia e culpa pelo parricídio. Falta que imporá ao grupo a criação de um monumento em homenagem ao pai morto, a fim de remediar ou velar aquela figura deturpada pelo ritual de extinção paterna. Deste modo, o totem em nome do pai erigido, será mais do que um mausoléu ou tumba, mas um cenotáfio (do grego

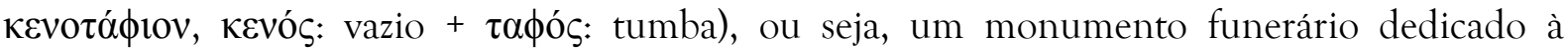
ausência, a ausência de um sóma $(\sigma \omega ́ \mu \alpha)$, ou de um corpo. Uma vez mencionadas tais particularidades presentes na hipótese freudiana, podemos ainda relacionar o totem supradito a um primeiro significante, o qual é inscrito no lugar de uma ausência. Determinados sujeitos, ditos pertencentes a certo contexto ou lugar discursivo, quando faltantes a esse lugar, impõem que seja erguido um monumento. Assim sendo, poderíamos relacionar a edificação de monumentos e ícones à culpa trabalhada por Freud. Inobstante, indo ao encontro do Capitalismo como Religião, de Walter Benjamin, onde o intelectual ao recuperar Max Weber, Ernst Bloch e Martin Buber, investirá sobretudo naquilo que será, na sua concepção, o disparo para a devoção religiosa e, consequentemente, da sensação inculcada pelo capitalismo. Qual seja, o termo Schuld que, no idioma alemão, remete tanto à ideia de culpa, quanto a de dívida. Neste sentido, o devoto de qualquer religião como o é o capitalismo, é culpado porque endividado e endividado porque culpado.

Diz-nos o intelectual Michel Löwy a partir da leitura que faz Walter Benjamin do fabuloso romance Die Rettung, ou "A Salvação", quarto livro da pensadora alemã Anna Seghers, em 1937 publicado na capital holandesa. O que nos diz Michel Löwy a respeito dessa fabulosa narração (Erzählung), que se debruça sobre a paixão ou o sofrimento do proletariado nas mãos dos nazistas, parte da analogia que faz Benjamin dos cronistas medievais a respeito do reino dos céus e a faz em contraponto ao terceiro Reich, este como a imagem inversa do reino de Deus. Assim sendo, Löwy chama nossa a atenção para o fato de os cronistas da Idade Média por vezes alertarem para o futuro aparecimento da figura de um anticristo, particularidade que naquelas 
narrativas exercia papel fundamental para a maquinaria da inculcação do terror e aquisição da devoção. Assim, Michel Löwy nos diz que o anticristo arremeda a benção do reino de Deus, em semelhante modo que o terceiro Reich representa um arremedo do Socialismo. Sendo a figura do anticristo um arremedo do messias ou do reino de Deus e igualmente o terceiro Reich um arremedo do Socialismo, concluiríamos que o diabólico anticristo seria, no contexto da época, protagonizado por Hitler e sua corja, que em seus Campos de Extermínio estandardizavam uma concepção historicamente cara ao calvinismo, isto é, que o trabalho é capaz, para não dizer que só ele é capaz, de libertar ou tornar livre (Die Arbeit Macht Frei). O trabalho árduo pode transformar o destino de um sujeito e leva-lo à salvação, ao reino dos céus.

Quando se refere à temática do destino, Noemi Jaffe relata que sua mãe acredita totalmente no destino. Assim como a narração do castigo da pedra erguida sobre a cabeça que em muito se assemelha aquele de Sísifo, a cena do vestido predileto é outra passagem emblemática do livro. Mas, como de fato ter tanta certeza do vestido que a acompanhou e este ter sido o mesmo que ela fisgou da pilha de roupas usadas, sem corpos, sem recheio, sem vida, um monte de peles sociais despidas de seus agentes? Quanto ao destino, deve-se somente submeterse; nem pensar sobre ele, nem buscar construi-lo autonomamente, nem desafiá-lo. Ele já está prescrito e ocorrerá por bem ou por mal. (JAFFE, p. 97).

Ao dizer isso, Noemi Jaffe faz ecoar parte da filosofia de sua mãe, Lili Jaffe. Sendo assim, podemos dizer que foram necessárias as guerras, seja para reforçar a demência humana, conferindo a ela (espécie humana) uma proficiência que é documentada em todos os relatos de sobreviventes, documentações cotidianas que relatam não só a continuidade e ininterrupção do mal, como também apontam, no caso de Noemi Jaffe e, particularmente, no relato de sua mãe, Lili Jaffe, que nenhum crime, por mais brutal e igualmente racional que seja, por mais que se debruce sobre a abstratização do ser humano, nenhum crime é perfeito e, igualmente, nenhuma utopia é possível, seja ela por parte daqueles que anseiam por um mundo apartado de uma determinada etnia, gênero ou classe social, seja por parte dos que anseiam por um mundo igualitário, sem guerra, de paz eterna. No entanto, é necessária a guerra para que reconheçamos os intervalos de paz mesmo que, em geral, não valorizemos esses intervalos: o homem belicoso é saudoso de sua guerra.

De alguma forma, podemos pensar ainda que o destino, em alguma medida, é como um artifício linguístico, quase mítico, particularidade que ocorre marcadamente em e através da linguagem, uma vez que é ela que permite a elaboração de tais coincidências. Noemi Jaffe, ao mencionar o destino como força que garante uma espécie de tranquilidade ao sobrevivente, lembra-se das peças da Grécia antiga em que

os personagens trágicos vestiam-se com roupas de bode, daí o nome tragédia, de tragos, bode. Seu canto, odia, se aproxima do canto de um animal caprino em agonia, na proximidade da morte; um canto alcoolizado, dionisíaco, de alguém cuja morte não assusta, por causa do estado de inconsciência. (JAFFE, pp. 97-98).

Nesse sentido, cabe ainda lembrar o ritual performado pelos judeus em que alguém toca uma espécie de berrante produzido com o chifre de um carneiro. Segundo a tradição judaica, o ritual do Shofar lembra a história da Akedá, lida durante o Rash Hashaná, ritual que remonta o episódio do sacrifício do carneiro, imolado casualmente por Avraham (Abraão) no lugar de seu filho único Yitschac (Isaac). Da mesma forma que o anjo alerta Abraão para que não mate seu 
filho, pois Deus já se deu por satisfeito em assistir o temor e, ao mesmo tempo, do que é capaz Abraão em Seu nome, também na narrativa mítica de Lili Jaffe, é como se o anjo de Abraão, narrado em Gênesis 22, ou mesmo o anjo da Anunciação, narrado em Lucas 1, tivessem guiado seu leve e delicado braço, quando ordenado pela oficial nazista na cena do vestido:

Quando eu cheguei no campo, estava com um vestido azul, de saia rodada. Os alemães pediram para nos despirmos e fizeram uma montanha com todas as nossas roupas. Depois da desinfecção, devíamos pegar, ao acaso, qualquer roupa do meio daquela pilha. Peguei justamente aquele meu vestido xadrez. (JAFFE, p. 97).

Essa narrativa pode muito bem ser questionada, assim como pela própria escrita da filha, quando menciona essa passagem, mas até que ponto importa chegar a algum consenso quanto a esse episódio? Talvez, nesse caso, não importe o que, de fato, aconteceu e sim o que Lili quis que tivesse acontecido, uma vez que, no caso dos sobreviventes, são também essas verdades, essa espécie de mitologia para a superação, essas pedras falsas no alguidar-miragem que permitem a sobrevivência diante do ocorrido. É como se a memória improvisasse as lembranças para conseguir manter vivo o seu protagonista, o sujeito que a integra. Lembra-nos, mais uma vez, Noemi Jaffe: São necessárias versões, mentiras, simulações, histórias para sobreviver. Para sobreviver, para sobreviver à sobrevivência, para continuar, para lembrar, para esquecer, para lembrar. (JAFFE, p. 146).

Já que mencionamos a improvisação, essa espécie de falseamento ou de adaptação de um determinado objeto ou narrativa em função de um uso, em função de uma sobrevivência; já que mencionamos esse falsear da aparência de um rasgo aberto numa superfície acetinada, podemos lembrar-nos de outra cena comentada por Noemi Jaffe à página 105, a partir do relato de sua mãe, Lili Jaffe. Lá, quando nos relata do frio intenso de 2009 e, sobretudo, de 1944, marcadamente a respeito da engenhosidade movida pela necessidade, ela cita Lili Jaffe: A gente tinha cobertores; a gente pegava um fio de feno, fazíamos uma agulha e com uma faca a gente cortava o cobertor e fazia um vestido. A alemã mostrava isso para todo mundo: "olha o que elas fizeram". (JAFFE, p. 105).

A partir desses apontamentos, podemos, inclusive, complementar as notas anteriores, dizendo que a improvisação no frio é um reflexo do movimento que oscila entre lembrar e esquecer e improvisar, um gesto da memória, esta que se vê obrigada a driblar toda e qualquer certeza em prol da sobrevivência, tanto do corpo quanto das próprias narrativas. Lembrar e esquecer são coisas muito parecidas. São processos mnemônicos seletivos, relacionados ao passado imediato ou distante - carregados de invenção e realidade. (JAFFE, p.165). Transformar um cobertor e um monte de feno em vestido é o equivalente a fisgar mnemonicamente um vestido, o preferido, numa pilha repleta de roupas.

Haben Kältegefühl, haben Durst, haben Hunger ou sentir frio, sentir sede, sentir fome, sensações que, aos poucos, vão fragilizando e consumindo por completo os sujeitos. Nesse sentido e tendo "O Que os Cegos estão Sonhando?" como ponto de partida, mas não só ele como todas as demais Literaturas de Testemunha produzidas após grandes massacres, podemos afirmar, junto à Noemi e Lili Jaffe, que a fome é a verdadeira morte, pois ou ela mata ou entrega o corpo ao perecimento, tendo em vista, talvez, a hipótese de que só o corpo são consegue e comete o suicídio. $\mathrm{O}$ corpo faminto não, pois gera a necessidade de vida para o pão prometido: 
Parece que a necessidade de comer, para quem passa fome, é mais forte do que a própria necessidade de viver. Havia poucos casos de suicídio nos campos de concentração, um gesto que não seria tão difícil. Era só atirar-se contra o arame eletrificado. Mas quase ninguém fazia isso; havia o próximo pão. Viver, assim, reduz-se praticamente a comer; ou melhor, comer é mais do que viver. (JAFFE, p. 107).

A fome é a porta da tortura, o pior castigo, aquele que nem mesmo Dante poderia dar-se conta de enfatizar, o castigo principal dos círculos posteriores a construção dantesca. Mas círculo e castigo esse que Noemi faz questão de frisar:

Toda a estratégia nazista de liquidação, de extermínio radical, além de assassinato direto, consistia em produzir fome. A fome é a pior privação, a mais bestial de todas e era ela que sustentava todo o processo paranoico e de extermínio da identidade humana e cultural dos prisioneiros. Não era somente uma dificuldade material e logística de enviar todos para as câmaras de gás; era uma etapa necessária do trabalho de diluição do homem no homem. Os campos de concentração são a fome; mais do que tudo é ela a determinante de todos os outros acontecimentos. (JAFFE, p.111).

Ler os relatos, ler toda a produção posterior a Arbeitsdorf, Auschwitz, AuschwitzBirkenau, Auschwitz Monowitz, Bardufoss, Belzec, Bergen-Belsen, Bolzano, Bredtvet, Breendonk, Breitenau, Buchenwald, Chełmno, Dachau, Falstad, Flossenbürg, Grini, GrossRosen, Herzogenbusch, Hinzert, Jasenovac, Kaufering, Kauen/Kovno, Klooga, Langenstein Zwieberge, Le Vernet, Lwów, Majdanek, Malchow, Maly Trostenets, Mauthausen-Gusen, Mittelbau-Dora, Natzweiler-Struthof, Neuengamme, Niederhagen, Oranienburg, Osthofen, Płaszów, Ravensbrück, Riga-Kaiserwald, Risiera di San Sabba, Sachsenhausen, Sobibór, Stutthof, Lager Sylt, Theresienstadt, Treblinka, Vaivara, Varsóvia, Westerbork é compreender o que diz Walter Benjamin a respeito não apenas da impossibilidade de narrar como a respeito do fracasso da Erfahrung, esta dependente da noção de coletividade minada pela guerra.

Tal como nos monumentos funerários que com o passar do tempo tomaram cada vez mais pra si o caráter de reforçar a história que precedera a decomposição do corpo, ressaltando os feitos que conformam aquela individualidade lá homenageada, também a literatura e as demais artes foram por vezes empregadas na perpetuação de determinados discursos e singularidades. Nesse sentido, podemos ressaltar uma particularidade da literatura e demais Artes, que através de seus labores, erigirem grandes mausoléus da humanidade, nos quais nem sempre repousa o corpo virtual dos tiranos e grandes opressores, ou pelo menos a representação de suas aparências, mas sim consistem no lugar aqui proposto como uma espécie de contramonumento, ambiente que, mais-que-visual assim como mais-que-verbal, dá voz e forma às infindáveis falas obliteradas pelas hegemonias discursivas, seja pelo dizer explícito, seja pelo nãodizer. O que é afinal dito quando aparentemente nada é dito?

\section{Referências:}

ADORNO, T.; HORKHEIMER, M. Dialética do Esclarecimento. Tradução de Guido de Almeida. 
Rio de Janeiro: Zahar, 1985.

ARENDT, H. Origens do Totalitarismo. Tradução de Roberto Raposo. São Paulo: Companhia das Letras, 2013.

ARENDT, H. Eichmann em Jerusalém. Tradução de José Rubens Siqueira. São Paulo: Companhia das Letras, 1999.

BENJAMIN, W. Obras Escolhidas I - Magia e Técnica, Arte e Política. Tradução de Sérgio Paulo Rouanet. São Paulo: Brasiliense, 2012.

BENJAMIN, W. Obras Escolhidas II - Rua de Mão Única. Tradução de Rubens Rodrigues Torres Filho e José Carlos Martins Barbosa. São Paulo: Brasiliense, 2012.

BENJAMIN, W. O Capitalismo como Religião. Tradução de Nélio Schneider. São Paulo: Boitempo, 2012.

EINSTEIN, C. Negerplastik. Tradução de Fernando Scheibe, Inês de Araújo. Florianópolis: UFSC, 2011.

FRAZER, J. G. Totemism. London: A. \& C. Black, 1887.

FRAZER, J. G. Totemism and Exogamy. London: Macmillan and Co. Limited, 1935

FREUD, S. Totem e Tabu. Tradução de Renato Zwick. Porto Alegre: L\&PM, 2013.

GAGNEBIN, J. M. Lembrar, Escrever, Esquecer. São Paulo: Editora 34, 2009.

GAGNEBIN, J. M. História e Narração em Walter Benjamin. São Paulo: Perspectiva, 2011.

JAFFE, N. O Que os Cegos Estão Sonhando?. Editora 34: São Paulo, 2012.

LE GOFF, J. História e Memória. Tradução de Bernardo Leitão. Campinas: UNICAMP, 1990.

LÉVI-STRAUSS, C. Totemismo Hoje. Tradução de Malcolm Bruce Corrie. Petrópolis: Vozes, 1975.

MElO NeTO, J. C. de. Obra Completa de João Cabral de Melo Neto. Rio de Janeiro: Nova Aguilar, 2003.

RIEGL, A. O Culto Moderno dos Monumentos: a sua essência e a sua origem. Tradução de Werner Rotchschild Davidsohn; Anat Falbel. São Paulo: Perspectiva, 2014.

SONTAG, S. Diante da dor dos outros. Tradução de Rubens Figueiredo. São Paulo: Companhia das Letras, 2003.

Recebido em: 03/05/2020

Aceito em: 15/06/2020 